\title{
Vamos aprender sobre a ação das enzimas?
}

Shall we learn about the action of enzymes?

Natália Rabello Pastore ${ }^{1}$, Juliana Castro Monteiro Pirovani ${ }^{2}$

${ }^{1}$ Programa de Pós-Graduação em Rede em Ensino de Biologia (PROFBIO), Universidade Federal do Espírito Santo, São Mateus, Espírito Santo, Brasil.

${ }^{2}$ Universidade Federal do Espírito Santo, Departamento de Ciências Agrárias e Biológicas, São Mateus, Espírito Santo, Brasil.

Autor para correspondência: Natália Rabello Pastore

EEEFM Professora Maria Cândido Kneipp

Rua Ronaldo Pereira, 274, Bairro Santa Cecília, CEP 29.380-000, Muniz Freire, Espírito Santo, Brasil

Tel: +55 $2899902-9089$

Email: nataliarpastore@gmail.com/natalia.pastore@educador.edu.es.gov.br

Submetido em 20/12/2020

Aceito em 21/12/2020 


\title{
RESUMO
}

O trabalho trata-se de uma proposta de atividade investigativa sobre o tema ações enzimáticas para as aulas de Biologia do ensino médio, tendo como objetivo compreender o conceito de proteína e enzima, enfocando na importância das enzimas na degradação do substrato e os fatores que influenciam a sua ação. Além disso, busca relacionar com as principais enzimas que atuam no organismo humano. A atividade contribuiu satisfatoriamente para a compreensão da ação enzimática sobre diferentes substratos, assim como a importância funcional das enzimas e demais proteínas no organismo humano.

Palavras-chave: Biologia. Atividade Enzimática. Proteína. Atividade Investigativa. Ensino.

\begin{abstract}
The work is a proposal for an investigative activity on the theme of enzymatic actions for high school Biology classes with the objective of understanding the concept of protein and enzyme, focusing on the importance of enzymes in the degradation of the substrate and the factors that influence your action. In addition, it seeks to relate to the main enzymes that act in the human organism. The activity contributed satisfactorily to the understanding of the enzymatic action on different substrates as well as the functional importance of enzymes and other proteins in the human body.
\end{abstract}

Keywords: Biology. Enzymatic Activity. Protein. Investigative Activity. Teaching.

Health and Biosciences, v.1, n.3, Dez. 2020

Disponível em: https://periodicos.ufes.br/healthandbiosciences 


\section{INTRODUÇÃO}

“As proteínas constituem a maior parte da massa seca de uma célula. Aquelas que são enzimas fornecem complexas superfícies moleculares no interior das células para as reações químicas" (ALBERTS, 2017, p. 109). As enzimas representam um caso especial de função proteica. "Elas se ligam a outras moléculas e as transformam quimicamente, ou seja, catalisam reações. As moléculas sobre as quais as enzimas exercem seus efeitos são chamadas de substratos da reação" (NELSON \& COX, 2014, p. 157).

Nesse contexto bioquímico torna-se fundamental que o estudante compreenda a forma de atuação das enzimas no organismo humano na degradação de diferentes substratos, assim como os fatores que alteram seu comportamento. Da Poian et. al (2010) ressaltam que não fosse as enzimas, o momento em que metabolizamos os nutrientes que ingerimos para gerar energia para diversos processos no organismo, a síntese e a quebra de compostos de alta energia para gerar a energia necessária para nossas atividades diárias poderiam acontecer em prazos que inviabilizassem nossa existência. Tais observações somadas aos conhecimentos prévios dos estudantes em relação ao tema constitui cenário ideal para que eles compreendam a dinâmica da ação enzimática. Delizoicov; Angotti; Pernambuco (2018) ressaltam a importância de iniciar os estudos a partir das ideias dos estudantes, como por exemplo a digestão do bife que o aluno comeu no almoço, tratando da relação ácido clorídrico e carne e introduzindo o conceito de catalizador biológico para a enzima pepsina. Do mesmo modo, analisar a especificidade enzimática da amilase salivar e sua atuação sobre diferentes substratos, como por exemplo, farinha de trigo, maisena, biscoito, macarrão e arroz cru. Outra reação enzimática que merece atenção é a análise do escurecimento detectado em alguns alimentos quando cortados, como maçã e pera. A partir dessas inquietações levantadas em sala de aula, os estudantes são conduzidos a desenvolver explicações para a atuação das enzimas. À luz da investigação, o docente faz-se mediador no processo de ensino e aprendizagem, orientando os estudantes a assumirem o protagonismo na construção do conhecimento através da observação, análise, elaboração de hipóteses e formas de testá-las, assim como a divulgação dos resultados alcançados (ZOMPERO \& LABURÚ, 2016).

Ter noção dos componentes bioquímicos que compõem o espaço celular é fundamental para a construção dos conhecimentos a nível médio tanto para os estudos em química quanto em biologia, de modo a fundamentar o saber em assuntos posteriores.

Health and Biosciences, v.1, n.3, Dez. 2020

Disponível em: https://periodicos.ufes.br/healthandbiosciences 


\section{OBJETIVOS}

$\checkmark$ Compreender o conceito de proteína e enzima.

$\checkmark$ Compreender a importância das enzimas na degradação do substrato, como no organismo - "sistema chave-fechadura".

$\checkmark$ Relacionar enzimas que atuam no organismo humano.

$\checkmark$ Identificar os fatores que influenciam a ação das enzimas tais como temperatura, $\mathrm{pH}$ e concentração do substrato.

\section{METODOLOGIA}

\section{Materiais utilizados}

- Copinhos ou tubos de ensaio;

- Tintura de iodo ou lugol;

- Água de torneira;

- Colher de chá;

- Conta gotas;

- Saliva humana;

- Alimentos: farinha de trigo, maizena, biscoito, macarrão, arroz cru, batata e maçã.

Jogo Roleta Proteica:

- Papel A4 - diversas cores;

- Papelão;

- Spinner (brinquedo);

- Canetas coloridas e pincéis;

- Cartolina;

- Papel contact;

- Cola;

- Régua;

- Tesoura sem ponta;

- EVA na cor vermelho (cor opcional);

- Compasso (opcional).

\section{Desenvolvimento}

A atividade realizou-se a partir de uma sequência didática desenvolvida em quatro aulas divididas em seis etapas - com o tema "Enzimas x substratos", com a participação de 20 estudantes de ensino médio. Na primeira aula - etapa 1 - o assunto foi introduzido a partir de 


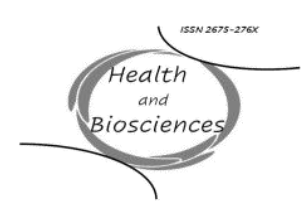

indagações direcionadas aos estudantes para reflexão sobre o tema proteínas e enzimas, de modo que eles identificassem a presença desses compostos em seu cotidiano, assim como sua importância para o metabolismo celular. Para aguçar a curiosidade e induzir à investigação diversos questionamentos foram apresentados aos estudantes, tais como: "Coloque um biscoito ou pipoca na boca e aguarde por um instante. O que acontece?"; "Pizza, lasanha ou bolo de chocolate: o que acontece com a produção de saliva ao pensarmos nesses alimentos?”; “Ao chegar da escola e adentrar à sua casa, você sente um cheiro muito agradável vindo da cozinha: o que acontece com seu corpo?"; "Por que salivamos tanto nas situações citadas?"; "Como é constituída a saliva?"; "Qual a função da saliva?”; “A saliva digere qualquer alimento?”; “Todas as enzimas são iguais? Por quê?”; "Por que a maçã e a batata ficam escuras ao serem cortadas?"; "Você conhece outros alimentos em que ocorra a mesma situação?"; “Como evitar que esses alimentos escureçam tão rapidamente?”; “Comer alimento 'escurecido' faz mal à saúde?”. Além de citar alimentos saborosos foram apresentadas imagens impressas desses alimentos para intensificar as reações bioquímicas nos corpos dos estudantes antes de comentar sobre o assunto. Do mesmo modo, permitir que os alunos façam seus próprios questionamentos, a partir de uma única situação-problema apresentada pelo professor, contribui satisfatoriamente para o desenvolvimento do potencial investigativo por parte dos estudantes. Foi solicitado aos estudantes que registrassem suas hipóteses, por escrito, relacionadas aos questionamentos apresentados. Assim, ainda nesta aula, foi proposta a realização de experimentos práticos - etapa 2 - referentes à atividade da enzima amilase salivar sobre diferentes substratos e a ocorrência do "escurecimento dos alimentos" maçãs e batatas, quando cortados, assim como os possíveis métodos/sugestões para se evitar o escurecimento. A turma foi dividida em seis grupos, dos quais três realizaram o experimento da detecção de amido e os outros três realizaram a observação da oxidação da maçã e da batata. Os experimentos foram realizados por todos os grupos, de modo que os grupos que realizaram a detecção de amido, posteriormente também realizaram a observação da batata e da maçã, e vice-versa. Esperava-se que os alunos conseguissem responder a alguns dos questionamentos provocados inicialmente, assim como levantar outras indagações pertinentes.

Na segunda aula - etapa 3 - após todos os grupos realizarem todos os experimentos sugeridos, proporcionou-se um momento de análise e discussão dos resultados por eles encontrados, bem como a comparação das ideias iniciais com aquelas obtidas após os experimentos. Nesse momento, o professor acrescentou à fala dos estudantes que o amido é 
fonte de reserva energética dos vegetais, acumulando-se geralmente nas sementes, raízes tuberosas (ex. cenoura, beterraba), caules tuberosos (ex. batata) e frutos. Para os alimentos ricos em amido, a digestão se inicia na boca, digerindo o amido e outros polissacarídeos (como o glicogênio) e os reduzindo em moléculas de maltose (dissacarídeo). Os sais na saliva neutralizam substâncias ácidas e mantêm, na boca, um pH levemente ácido, ideal para a ação da amilase salivar (ou ptialina).

No instante em que a tintura de iodo entra em contato com o alimento que contém amido, ocorre a formação de um complexo amido/lugol que possui uma cor característica (azul escuro ou roxo). Como a ptialina converte as moléculas de amido em moléculas de maltose - "sistema chave-fechadura" - o complexo que foi formado anteriormente é desfeito e isso é observado pelo desaparecimento de sua cor.

Finalmente, explicar que na maçã e na batata e em alguns outros vegetais como pêssego, pera, banana e abacate, por exemplo, alguns compostos sofrem oxidação pela ação da enzima polifenol oxidase quando expostos ao ar, e nesse processo formam produtos que, por sua vez, polimerizam - formam cadeias longas - apresentando cor cada vez mais escura. Explique, também, que as enzimas são proteínas com propriedades de catálise. Essas proteínas podem ser desnaturadas usando calor ou outras condições. É importante realçar, ainda, que ingerir alimentos "escurecidos" não traz riscos à saúde. Nessa etapa é bastante natural os estudantes indagarem sobre os modos de se evitar o escurecimento dos alimentos, propor hipóteses e desejar testá-las em sala de aula, o que torna a investigação ainda mais interessante. Assim, surgiram novas hipóteses tais como deixar o vegetal de molho em água fria, escaldar, colocar na geladeira ou em saco fechado, pingar limão ou vinagre, salgar ou adoçar, entre outras.

Na terceira aula - etapa 4 - os estudantes decidiram por testar as novas hipóteses: pingar limão sobre a maçã (a), colocar em saco fechado (b), salgar e adoçar (c). Entusiasmados para o teste da hipótese "a", os estudantes se surpreenderam com o não escurecimento da fruta e explicaram a situação para os colegas com a justificativa de que "o ácido impede a oxidação dos componentes da maçã”. Junto aos colegas do grupo, o professor acrescentou que o limão possui ácido cítrico, que funciona como um potente antioxidante natural. Ao entrar em contato com a maçã, o limão neutraliza a ação da oxidação, impedindo que a maçã escureça. Alguns estudantes quiseram comer a fruta para verificar se o sabor havia sido conservado, o que causou surpresa, pois identificaram pequena alteração no sabor. No teste da hipótese "b", os alunos disseram já imaginar o resultado, pois impedindo o contato da maçã com o ar a fruta não altera 
sua cor. No teste da hipótese "c", os estudantes identificaram que ao colocar o sal diretamente sobre a fruta o local conservou a cor natural, porém os arredores que não continham tanto sal começaram a escurecer. No entanto, quando fatiaram a maçã e a colocaram em contato com água salgada, após alguns minutos observaram que a fruta conservou sua coloração natural. Justificaram com os colegas "que as reações químicas entre o sal e os componentes da maçã impediam o escurecimento, ao menos por algum tempo, porque depois volta a escurecer”. Os alunos puderam constatar também que o açúcar não impede o escurecimento da maçã. Juntos e organizados em círculo, estudantes e professor analisaram e discutiram sobre os resultados obtidos quanto à ação das enzimas sobre cada substrato. A culminância deste momento oportunizou aos estudantes o conhecimento referente à enzima, proteína, substrato, energia, importância do trabalho enzimático e sua ação no organismo humano, assim como a identificação de fatores que influenciam a ação das enzimas tais como temperatura, $\mathrm{pH}$ e concentração do substrato.

Ainda nesta aula, por sugestão dos estudantes, discutiu-se a confecção de um jogo denominado Roleta Proteica - etapa 5 - a partir do conhecimento construído sobre proteínas, enzimas e substrato, para apresentação para a classe. Nesta etapa, o aluno utilizou os conhecimentos construídos em sala de aula a partir das discussões com os colegas para a confecção das peças da roleta. Em grupos, elaboraram as regras do jogo e perguntas sobre o tema em diferentes níveis de complexidade. A escolha da diagramação, cores, tamanho, pontuação e impressão gráfica da roleta foram sugeridos aos grupos como tarefa para casa.

Na quarta aula, em grupos, os estudantes jogaram a Roleta Proteica - etapa 6 - (descrito a seguir).

Como sugestão de avaliação à sequência didática podem ser consideradas as argumentações na discussão inicial, participação na realização e discussão do experimento e a construção e apresentação do jogo Roleta Proteica em sala de aula.

\section{Jogo Roleta Proteica}

O Roleta Proteica (Figura 1) é um jogo de perguntas e respostas com base nos conhecimentos construídos pelos estudantes nas aulas de Biologia sobre o tema proteínas. Pode ser jogado em grupos - o professor decide a quantidade de alunos por grupo - ou um momento único com toda a classe, onde a roleta é utilizada por todos em diferentes momentos. No caso da formação de grupos, pode ser eleito um representante de cada grupo para jogarem juntos. O jogo é composto

Health and Biosciences, v.1, n.3, Dez. 2020

Disponível em: https://periodicos.ufes.br/healthandbiosciences 
de uma roleta que contém as pontuações indicadas por cores diversas; 3 envelopes com perguntas de níveis complexo, intermediário e menos complexo (descritas a seguir) e 1 envelope com as regras e orientações do jogo (Figura 2).

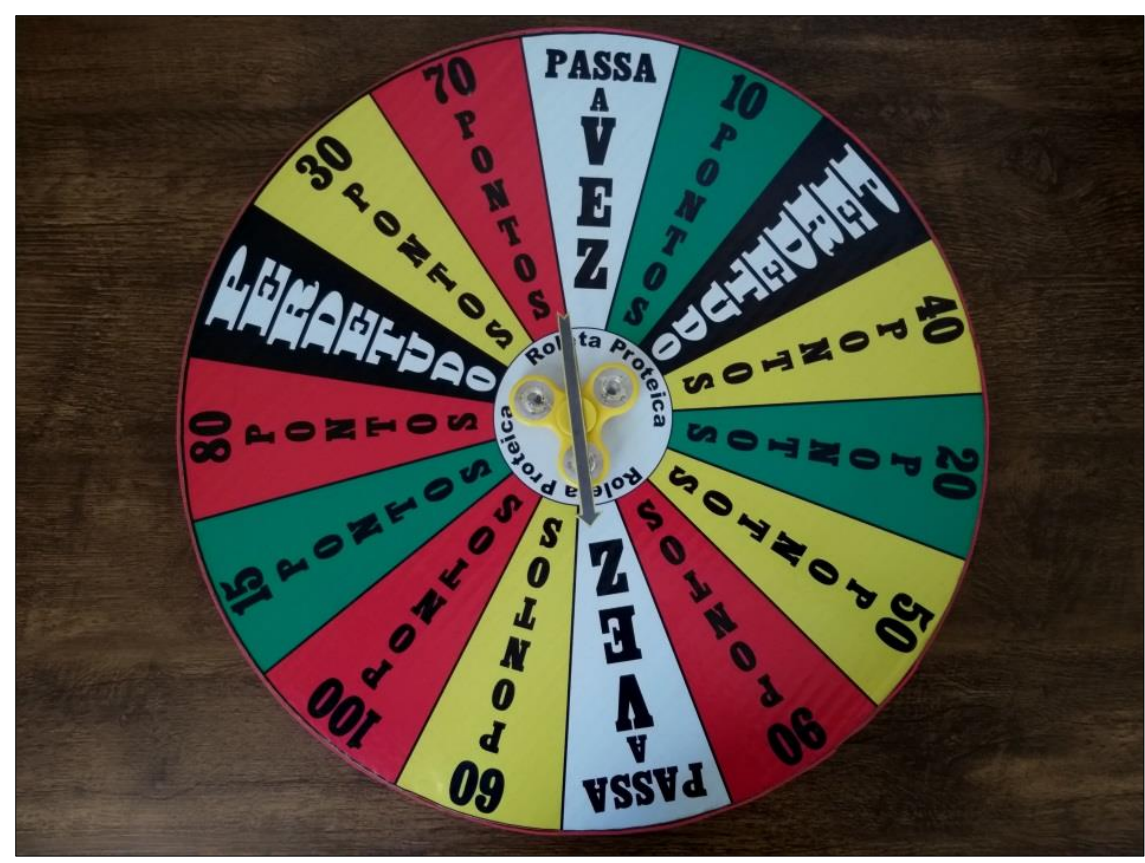

Figura 1. Jogo intitulado "Roleta proteica", construída pelos alunos.

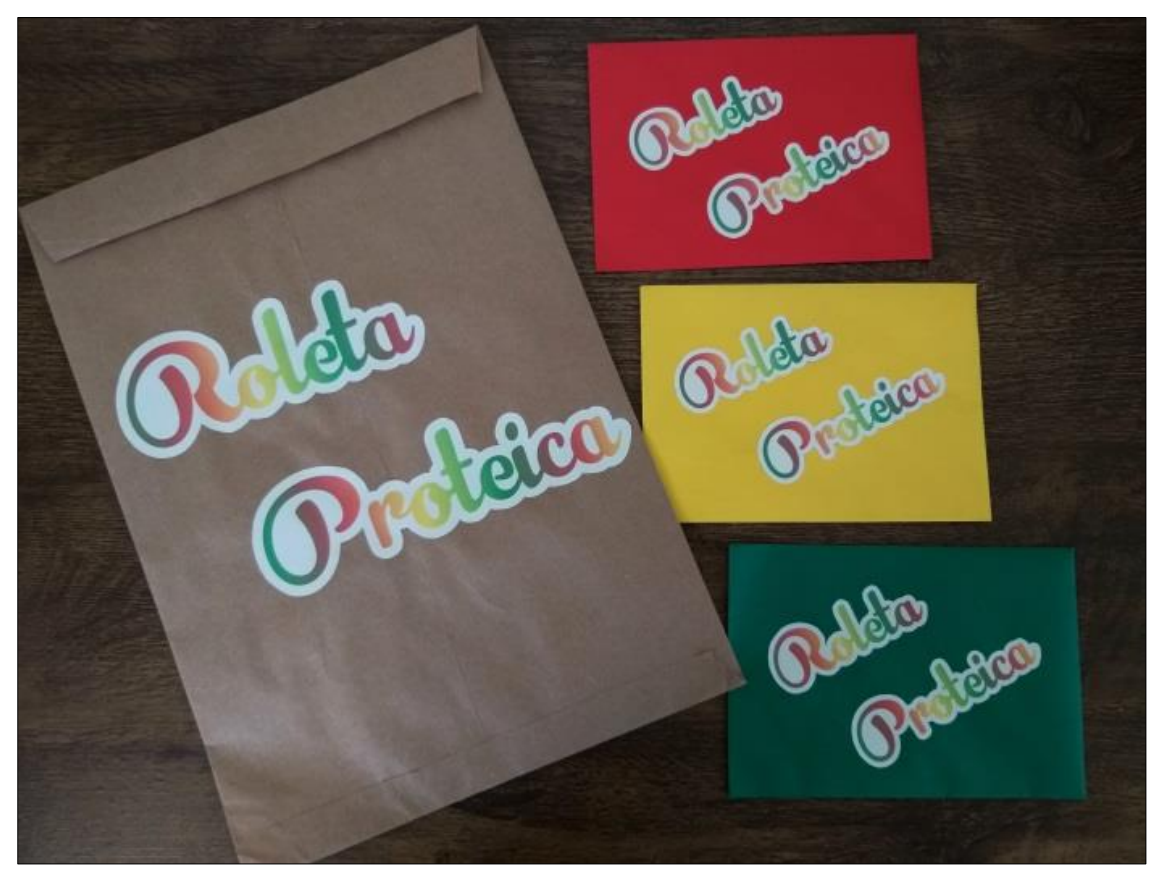

Figura 2. Informações do Jogo Roleta Proteica: envelope maior contém as regras gerais para os participantes e envelopes menores as perguntas sobre "Proteínas", nos níveis menos complexo (verde), intermediário (amarelo) e mais complexo (vermelho).

Health and Biosciences, v.1, n.3, Dez. 2020

Disponível em: https://periodicos.ufes.br/healthandbiosciences 
Quantos às regras e, considerando uma roleta para toda a classe, um aluno que se dispor a começar deve rodar e, ao parar a seta, responder a uma pergunta referente à cor indicada no triângulo da roleta. Cada triângulo contém uma cor que indicará uma pontuação e uma pergunta.

Diante do acerto da resposta é atribuída a respectiva pontuação ao participante e ele segue girando a roleta. Em caso de erro, a pontuação não será atribuída ao participante e o próximo aluno - ou o oponente - segue o jogo. Caso esgotem as perguntas de qualquer um dos envelopes, passa a valer a cor - com respectiva pergunta e pontuação - indicada no triângulo à direita.

O Jogo Roleta Proteica enfatiza o estudo das proteínas e enzimas, podendo ser utilizado para introduzir o assunto, de modo a verificar o que os alunos sabem a respeito do conteúdo e/ou posteriormente na culminância do mesmo. As indagações apresentadas no jogo propõem a busca por respostas de acordo com os conhecimentos prévios dos estudantes ou aqueles construídos ao longo do processo de ensino e aprendizagem, de modo que a investigação - no início ou ao final do percurso - permita ao aluno identificar, refletir, revisar e inferir a respeito dos conceitos em Bioquímica Celular - proteínas e enzimas.

Perguntas do jogo roleta proteica:

- Perguntas de nível mais complexo (envelope vermelho):

- Explique a doença anemia falciforme, informando também sinais e sintomas.

- Cite os aminoácidos considerados essenciais ao organismo.

- Escreva na lousa o grupamento funcional das proteínas.

- Cite 5 proteínas: 1 com ação catalítica e outras 4 que constituem o organismo humano.

- Explique a ação específica das enzimas.

- Qual a função do grupo heme nas proteínas?

- Cite o substrato no qual agem, respectivamente, as enzimas lactase, maltase, sacarase, galactase e amilase.

- Onde é realizada a digestão de amido, de lipídio e de proteína no organismo humano?

- Perguntas de nível intermediário (envelope amarelo):

- Quais fatores podem alterar a ação enzimática? 
- O que são aminoácidos naturais e aminoácidos essenciais?

- Por que alguns alimentos como a batata, a maçã e o abacate escurecem ao serem cortados? Explique;

- Cite um carboidrato presente no leite.

- O que fazer para evitar o escurecimento dos alimentos?

- A sacarase atua sobre a lactose. F ou V? Explique.

- Desenhe, na lousa, a estrutura primária, secundária e terciária de uma proteína.

- Cite uma proteína presente no leite.

- Perguntas de nível menos complexo (envelope verde):

- Como são classificadas, quimicamente, as enzimas?

- O que é proteína?

- O que é enzima?

- Cite uma enzima que digere os carboidratos.

- Cite quatro alimentos digeridos inicialmente na boca.

- O que são aminoácidos?

- Toda enzima é uma , mas nem toda é uma enzima.

- A enzima atua sobre o

\section{PONTOS INVESTIGATIVOS DA ATIVIDADE}

A atividade apresenta alguns pontos investigativos, tais como o envolvimento dos alunos em sua aprendizagem, quando colocados diante de situações-problema, como a análise das imagens dos alimentos e a descrição biológica - hipotética - do que ocorre em seu organismo; a formulação de hipóteses sobre a atuação das enzimas sobre diferentes substratos; a coleta e registro dos dados em relatórios; assim como as inferências sobre os resultados obtidos. Vale ressaltar a participação ativa dos estudantes nas discussões, comparando, corrigindo, indagando, analisando evidências e partilhando suas dúvidas e conceitos sobre o assunto.

Para garantir o potencial investigativo da atividade, sugere-se colocar os estudantes

Health and Biosciences, v.1, n.3, Dez. 2020

Disponível em: https://periodicos.ufes.br/healthandbiosciences 


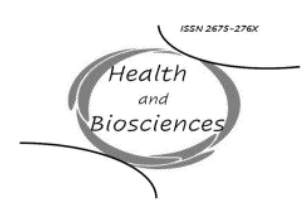

frente a uma situação-problema - "o que acontece com a produção de saliva ao pensarmos em alimentos como pizza, lasanha ou bolo de chocolate?” - e motivá-los a investigar tal situação. Os conhecimentos prévios dos alunos foram considerados ponto de partida para explorar o tema, de modo que o professor mediador foi revelando, aos poucos, as lacunas em relação ao conhecimento sobre proteínas e enzimas. "É com base nesses conhecimentos anteriores e da manipulação do material escolhido que os alunos vão levantar suas hipóteses e testá-las para resolver o problema" (CARVALHO, 2013, p. 11). Diante da problemática, os alunos precisaram planejar suas ações, registrar dados, interpretar os resultados, tirar conclusões e avaliar em que medida a investigação lhes trouxe respostas.

\section{CONSIDERAÇÕES}

A atividade contribuiu satisfatoriamente para a compreensão da ação enzimática sobre diferentes substratos assim como a importância funcional das enzimas e demais proteínas no organismo humano. Os experimentos, na prática, auxiliaram os alunos não apenas no estudo do conteúdo, mas também oportunizando a vivência do método científico quando foram colocados diante de uma situação-problema. Assim, os estudantes apresentaram-se bastante interessados na realização das atividades propostas, envolvendo-se em sua aprendizagem na organização das práticas, comparando as misturas obtidas, analisando e registrando os resultados em relatório, discutindo ativamente e avaliando todo o processo. Muitos questionamentos surgiram em meio a investigação, o que enriqueceu ainda mais as discussões coletivas e possibilitaram, ainda, novos testes para averiguar novas hipóteses. Os alunos demonstraram-se motivados em descobrir o "resultado final", ou seja, o que era produzido em cada novo teste ou mistura de alimentos. Tal motivação na busca por um resultado caracteriza o viés investigativo da atividade proposta e demonstra o protagonismo do estudante para com sua aprendizagem.

Quanto à realização da atividade com as turmas de nível médio, temos que o tempo das aulas de biologia é um tanto desafiador para o desenvolvimento de práticas investigativas em todas as suas etapas. Acredito que precisamos reorganizar nossa ação didática de modo a permitir que o aluno construa hipóteses sobre uma situação-problema e possa testá-las com mais tempo, em sala de aula. Além disso, que os próprios alunos possam identificar problemas ou interrogativas que representem suas inquietações sobre qualquer assunto apresentado pelo professor ou outro de seu interesse.

Health and Biosciences, v.1, n.3, Dez. 2020

Disponível em: https://periodicos.ufes.br/healthandbiosciences 
Alguns pontos podem ser modificados na utilização desta sequência de ensino, de acordo com a intencionalidade pedagógica de cada docente. As perguntas sobre proteínas, em diferentes níveis de complexidade, por exemplo, podem ser elaboradas por cada turma ao invés de adotar as perguntas sugeridas aqui. De acordo com as construções em sala de aula e sob orientação do professor, estudantes, em grupos, podem elaborar seus questionamentos sobre o tema contemplando sua realidade.

Como sugestão de leitura e práticas sobre o assunto temos a Revista Nova Escola, com a matéria "A Química que dá gosto aprender", disponível em https://novaescola.org.br/conteudo/3064/a-quimica-que-da-gosto-aprender, que a partir de experiências simples demonstra como se dá a digestão no corpo humano e pode tornar as aulas ainda mais interessantes.

\section{AGRADECIMENTOS}

O presente trabalho foi realizado com o apoio da Coordenação de Aperfeiçoamento de Pessoal de Nível Superior - Brasil (CAPES) - Código de financiamento 001.

\section{REFERÊNCIAS BIBLIOGRÁFICAS}

\section{ALBERTS B, JOHNSON A, LEWIS J, MORGAN D, RAFF M, ROBERTS K, WALTER} P, WILSON J, HUNT T. Biologia molecular da célula, 6.ed., Porto Alegre: Artmed, 2017, $1464 p$.

2. CARVALHO AMP. O ensino de ciências e a proposição de sequências de ensino investigativas. In: Carvalho AMP, Oliveira CMA, Scarpa DL, Sasseron LH, Sedano L, Batistoni e Silva M, Capecchi MCVM, Abib MLVS, Briccia V editores. Ensino de ciências por investigação: condições para implementação em sala de aula. São Paulo: Cengage Learning, 2013. p. 1-20.

3. DA POIAN A, FOGUEL D, DANSA-PETRETSKI M, MACHADO OT, ABREU-FIALHO AP. Bioquímica I, 5.ed., Rio de Janeiro: Fundação CECIERJ, 2010.

4. DELIZOICOV D, ANGOTTI JA, PERNAMBUCO MM. Ensino de Ciências: fundamentos e métodos, 5.ed., São Paulo: Cortez, 2018, 288p.

Health and Biosciences, v.1, n.3, Dez. 2020 
5. NELSON DL, COX MM. Princípios de Bioquímica de Lehninger, 6.ed., Porto Alegre: Artmed, 2014, 1328p.

6. ZOMPERO A de F, LABURÚ CE. Atividades Investigativas para as aulas de Ciências, Curitiba: Appris, 2016, 141p. 